\title{
Prevalence of Renal Failure in Children and the Need for Dialysis in Paediatric Nephrology in a Developing Country
}

\author{
Younoussa Keita', Aliou A. Ndongo', Fatou Ly' ${ }^{2}$, Ndeye C. Cisse', Liliane N. D. M. Yamba ${ }^{3}$, \\ Babacar Niang', Djiby Seck1, Amadou Sow ${ }^{4}$, Ndeye F. Sow ${ }^{1}$, Abou Ba ${ }^{5}$, Indou D. Ly' \\ Aliou Thiongane ${ }^{3}$, Amadou L. Fall ${ }^{3}$, Idrissa D. Ba ${ }^{3}$, Modou Gueye ${ }^{4}$, Pape M. Faye ${ }^{3}$, Assane Sylla ${ }^{1}$ \\ ${ }^{1}$ Pediatric Unit of Aristide Le Dantec Hospital, Dakar, Senegal \\ ${ }^{2}$ Pediatric Unit of Pikine Hospital, Dakar, Senegal \\ ${ }^{3}$ Pediatric Unit of Albert Royer Hospital, Dakar, Senegal \\ ${ }^{4}$ Pediatric Unit of Abass Ndao Hospital, Dakar, Senegal \\ ${ }^{5}$ Pediatric Unit of Dalal Diam Hospital, Dakar, Senegal \\ Email: *younouss_keith@yahoo.fr
}

How to cite this paper: Keita, Y., Ndongo, A.A., Ly, F., Cisse, N.C., Yamba, L.N.D.M., Niang, B., Seck, D., Sow, A., Sow, N.F., Ba, A., Ly, I.D., Thiongane, A., Fall, A.L., Ba, I.D., Gueye, M., Faye, P.M. and Sylla, A. (2022) Prevalence of Renal Failure in Children and the Need for Dialysis in Paediatric Nephrology in a Developing Country. Open Journal of Nephrology, 12, 101-111. https://doi.org/10.4236/ojneph.2022.121010

Received: January 18, 2022

Accepted: February 28, 2022

Published: March 3, 2022

Copyright ( 2022 by author(s) and Scientific Research Publishing Inc. This work is licensed under the Creative Commons Attribution International License (CC BY 4.0).

http://creativecommons.org/licenses/by/4.0/ (c) (i) Open Access

\begin{abstract}
Background: Renal failure is among the major visceral failures responsible for morbidity and mortality in children. Epidemiological data on renal failure in children are limited in sub-Saharan Africa, including Senegal. We conducted this study to assess the prevalence of renal failure $(\mathrm{RF})$ and the need for dialysis in the paediatric nephrology unit. Patients and methods: This was a retrospective and descriptive study in the pediatric nephrology unit from $1^{\text {st }}$ January 2020 to 30 June 2021, including children with acute or chronic RF. The need for dialysis was judged to be met by its effectiveness in face of an indication. The data collected were analysed on sphinx plus 2017 software. Results: The prevalence of $\mathrm{RF}$ was $60 \%(\mathrm{n} / \mathrm{N}=132 / 220)$. RF was acute in $59 \%(\mathrm{n} / \mathrm{N}=78 / 132)$ of cases. The mean age was $6.53 \pm 4.77$ years with a sex ratio of 1.8. The mean serum creatinine level was $27.22 \mathrm{mg} / \mathrm{L}(240.9$ $\mu \mathrm{mol} / \mathrm{L}$ ) and $\mathrm{BUN}$ at $0.85 \mathrm{~g} / \mathrm{L}$. The aetiologies were dominated by prerenal AKI (Acute Kidney Injury) complicating nephrotic syndrome (NS) in $37.2 \%$ $(\mathrm{n} / \mathrm{N}=29 / 78)$ and dehydration due to stomach flu in $17.6 \%(\mathrm{n} / \mathrm{N}=9 / 51)$. Acute post-infectious glomerulonephritis including group A streptococcus and plasmodium falciparum accounted for $16.7 \%(\mathrm{n}=13 / 78)$ of intrinsic AKI. The need for dialysis was unmet in $50 \%(\mathrm{n} / \mathrm{N}=7 / 14)$ with a mortality of $14.1 \%(\mathrm{n} / \mathrm{N}=11 / 78)$. The mean age of the patients with chronic RF was 8.68 \pm 4.74 years with a sex ratio of 2.6. The mean serum creatinine level was 36.56 $\mathrm{mg} / \mathrm{L}(323.5 \mu \mathrm{mol} / \mathrm{L})$ and the BUN level was $0.99 \mathrm{~g} / \mathrm{L}$. Half of the children were classified as having CKD stage II (early stage). The aetiologies were
\end{abstract}


dominated by primary focal and segmental glomerulosclerosis (FSGS), 53.7\% $(\mathrm{n} / \mathrm{N}=29 / 54)$, renal hypoplasia, $22.2 \%(\mathrm{n} / \mathrm{N}=12 / 54)$ and reflux nephropathy, $29.4 \%(\mathrm{n} / \mathrm{N}=5 / 17)$. The need for dialysis was unmet in $46.1 \%(\mathrm{n} / \mathrm{N}=$ 6/13). The overall mortality of chronic kidney disease (CKD) with RF was $29.6 \%(\mathrm{n} / \mathrm{N}=8 / 27)$. Conclusion: The prevalence of RF was high in the unit. Most aetiologies of AKI were accessible to prevention. Only half of the children had access to free dialysis, hence the need for a dedicated pilot dialysis centre.

\section{Keywords}

Renal Failure, Glomerulonephritis, Hypodysplasia, Dialysis, Children

\section{Introduction}

Acute kidney injury (AKI) and chronic kidney disease (CKD) with RF are among the major visceral failures responsible for morbidity and mortality in sub-Saharan Africa [1] [2]. Screening for RF in paediatric nephrology can be done by estimating glomerular filtration rate (GFR) in children using blood creatinine level, ideally measured by traceable enzymatic techniques. It is the most commonly used marker of GFR in routine practice [3]. GFR can be estimated in children using the simplified Schwartz formula, which was adjusted to the new creatinine measurement methods in 2009 [4] [5]. Its value obtained by a calculator should be compared to the age and gender-specific standards for paediatrics [6] [7]. The main objective of this work was to estimate the prevalence of RF in the paediatric nephrology unit based on the systematic calculation of GFR in consulting children, to identify its aetiologies and to develop management and prevention strategies in our developing country.

\section{Patients and Methods}

This was a retrospective and descriptive study conducted in the nephrology unit of the paediatric department of Aristide Le Dantec Hospital. Patients were referred from various paediatrics structures and health facilities in Dakar and its suburbs, and sometimes from neighbouring countries. In this unit, 2 paediatric nephrologists were in charge of consultation, diagnosis in a hospital or during follow-up, dialysis and renal biopsy. The biopsy slides were read by light microscopy by a renal histopathologist. Immunofluorescence (IF) and electron microscopy (EM) were not available at the time of the study. Haemodialysis and peritoneal dialysis are free of charge for families and available in the adult dialysis centre of the hospital. The study was conducted from $1^{\text {st }}$ January 2020 to 30 June 2021. Serum creatinine level was systematically measured on the admission of the child and in the laboratory by the modified Jaffee method. The value obtained was compared with the norms for age [8]. Routine calculation of GFR was performed using the new Schwartz 2009 formula where GFR $=(36.5 \times$ height in 
$\mathrm{cm}) /($ serum Creatinine level in $\mu \mathrm{mol} / \mathrm{L})$, (serum Creatinine level in $\mu \mathrm{mol} / \mathrm{L}=$ serum Creatinine level in $\mathrm{mg} / \mathrm{L} \times 8.85$ ) [6] [9]. Height was measured in $\mathrm{cm}$ by the paediatrician on duty using a fixed stadiometer. The result of the GFR calculation expressed in $\mathrm{ml} / \mathrm{min} / 1.73 \mathrm{~m}^{2}$ was compared with the norms for age [10]. Unusable records were not included in this work. A child was considered to have RF if the GFR was below the norm for age. Children with a normal GFR were excluded from the study. We included in this work all children with RF. Any recent, reversible RF with normalization of GFR with treatment was considered as AKI. Otherwise, it was an RF in the context of chronic kidney disease (CKD) which we systematically classified into five stages according to the level of GFR alteration [11]. The nosology's aetiologies of AKI and chronic renal failure was made after comparing clinical and paraclinical data. The tolerance of RF was systematically evaluated during AKI and advanced stages of CKD. The indication for dialysis was determined by the presence and persistence of at least one of the following signs of intolerance in any patient with renal failure despite adequate symptomatic treatment: anuria, metabolic acidosis, major increased level of blood urea nitrogen (BUN), acute pulmonary oedema, high blood pressure, active bleeding, hypocalcaemia, hyperkaliemia \pm electrical signs, hypernatremia, or hyponatremia [12]. The need for dialysis was judged to be met by its effectiveness in face of an indication. AKI and CKD's mortality and mortality by access to dialysis or not were reported. The data collected were entered and analysed with the sphinx plus 2 V5 2017 software. Quantitative variables were presented as means with their ranges. Qualitative variables were expressed as percentages.

\section{Results}

\subsection{Prevalence of Renal Failure}

During the study period, 258 patients were seen in the department. The records of 38 children were unusable, so 220 children with renal disease were analysed. $\mathrm{RF}$ was present at admission in $60 \%$ of children $(\mathrm{n} / \mathrm{N}=132 / 220)$. At consultation, prevalence was $59.1 \%(\mathrm{n} / \mathrm{N}=78 / 132)$ for $\mathrm{AKI}$ and $40.1 \%(\mathrm{n} / \mathrm{N}=54 / 132)$ for CKD with RF (Figure 1).

\subsection{Diagnostic, Therapeutic and Evolutionary Characteristics of AKI}

For children with AKI, the mean age was $6.53 \pm 4.77$ years with a sex ratio of 1.8. The mean serum creatinine level was $27.22 \mathrm{mg} / \mathrm{L}(240.9 \mu \mathrm{mol} / \mathrm{L})$ and BUN at $0.85 \mathrm{~g} / \mathrm{L}$. Socio-demographic, clinical and biological characteristics of the patients are shown in Table 1. Aetiologies were dominated by pre-renal AKI complicating nephrotic syndrome in $37.2 \%(\mathrm{n} / \mathrm{N}=29 / 78)$, dehydration from stomach flu in $17.6 \%(\mathrm{n} / \mathrm{N}=9 / 51)$ and sepsis in $7.8 \%(\mathrm{n} / \mathrm{N}=4 / 51)$. Intrinsic AKI was represented by post-infectious acute glomerulonephritis (PIAGN) 16.7\% (n $=13 / 78)$ including group A streptococcus and plasmodium falciparum. Acute pyelonephritis (APN) accounted for $77.7 \%(\mathrm{n} / \mathrm{N}=7 / 9)$ of acute tubulointerstitial 
Table 1. Socio-demographic, clinical, biological characteristics, dialysis requirement and mortality by type of RF.

\begin{tabular}{ccc}
\hline $\begin{array}{c}\text { Socio-demographic, clinical and } \\
\text { biological characteristics, dialysis } \\
\text { requirement, and mortality }\end{array}$ & AKI & CKD with RF \\
\hline Mean age (years) & $6.53 \pm 4.77$ & $8.68 \pm 4.74$ \\
Sex-ratio & 1.8 & 2.6 \\
Anurie (\%) & 32 & 24 \\
Acute pulmonary oedema (\%) & 21 & 15 \\
Acidosis (\%) & 13 & 17 \\
BUN (g/L) & 0.85 & 323.5 \\
Serum Creatinine level ( $\mu$ mol/L) & 240.9 & $53.62 \pm 34$ \\
Mean GFR (ml/min/1.73m $\left.{ }^{2}\right)$ & $53.19 \pm 31$ & 30 \\
Hyperkalemia (\%) & 62 & $13(48.1)$ \\
Dialysis need n $(\%)$ & $14(18)$ & $6(46.1)$ \\
Unmet need for dialysis n (\%) & $7(50)$ & $8(29.6)$ \\
Overall mortality n $(\%)$ & $11(14.1)$ & $4(67)$ \\
\hline Mortality in case of no access to dialysis n $(\%)$ & $6(85.7)$ & \\
\hline
\end{tabular}

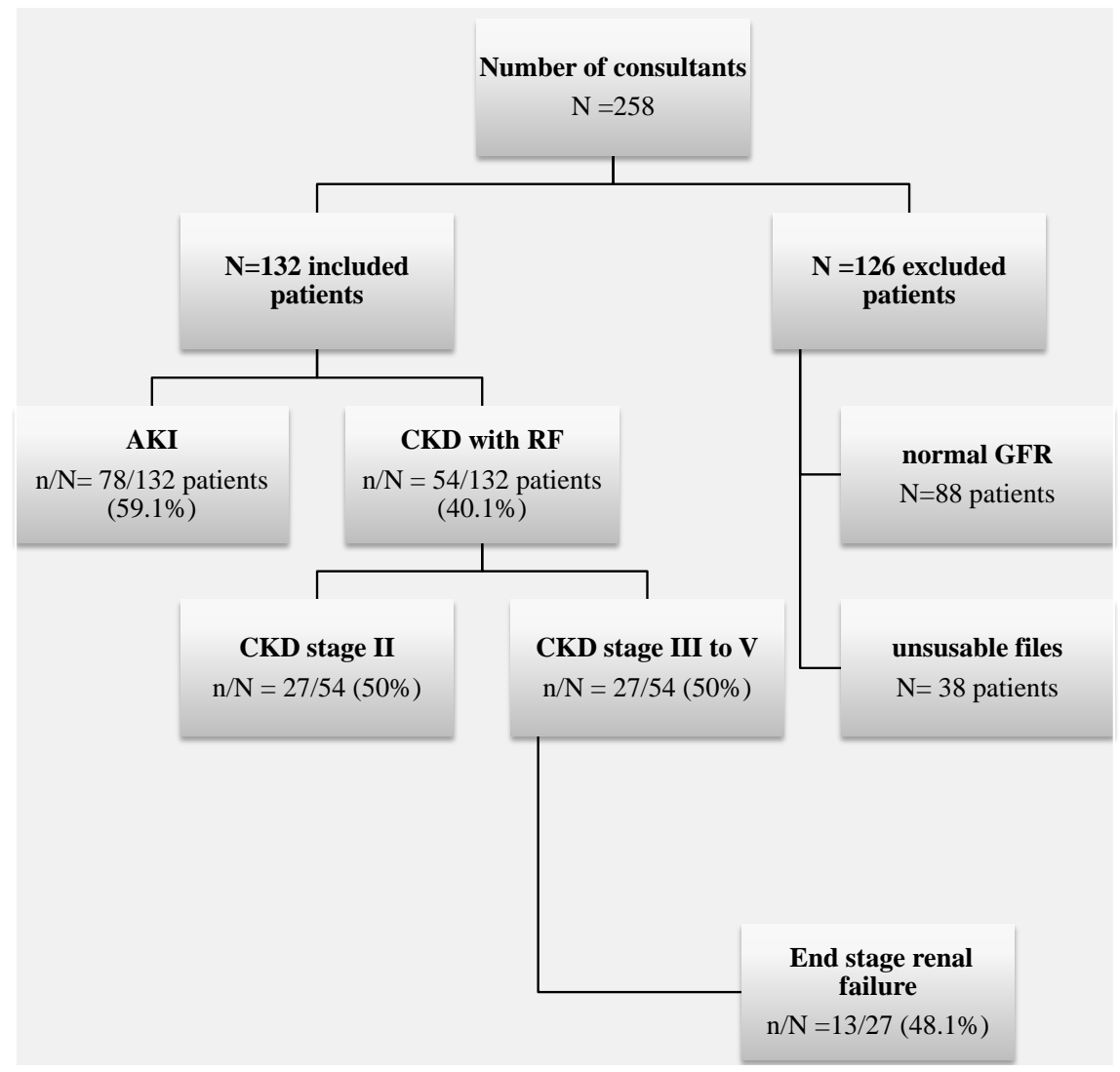

Figure 1. Prevalence and classification of renal failure in the paediatric nephrology unit of Le Dantec Hospital. GFR = glomerular filtration rate; RF = renal failure; AKI = acute kidney injury; $\mathrm{CKD}=$ chronic kidney disease; $\mathbf{n}=$ number of people in the variable under study; $\mathbf{N}=$ total number of people. 
nephritis (ATN). The topographical classification of AKI aetiologies is shown in Figure 2. Indications for dialysis were present in $18 \%(\mathrm{n} / \mathrm{N}=14 / 78)$ dominated by hyperkaliemia (62\%), anuria (32\%) and acute pulmonary oedema (21\%). Half of the children with AKI had dialysis access. Among them, $71.4 \%$ were on haemodialysis (HD) and $28.6 \%$ on peritoneal dialysis (PD). The unmet need for dialysis was $50 \%(\mathrm{n} / \mathrm{N}=7 / 14)$. The overall mortality of AKI was $14.1 \%(\mathrm{n} / \mathrm{N}=11 / 78)$ (Table 1). AKI mortality was $78.5 \%(\mathrm{n} / \mathrm{N}=11 / 14)$ in case of dialysis indications and $85.7 \%(\mathrm{n} / \mathrm{N}=6 / 7)$ in case of no access to dialysis treatment.

\subsection{Diagnostic, Therapeutic and Evolutionary Characteristics of CKD with Kidney Failure}

In CKD with kidney failure, the mean age of children was $8.68 \pm 4.74$ years with a sex ratio of 2.6. The mean serum creatinine level was $36.56 \mathrm{mg} / \mathrm{L}(323.5 \mu \mathrm{mol} / \mathrm{L})$ and the BUN level was $0.99 \mathrm{~g} / \mathrm{L}$. Socio-demographic, clinical and biological characteristics of the patients are shown in Table 1. Half of the children were classified as having CKD stage II (early stage). The other half were classified as CKD

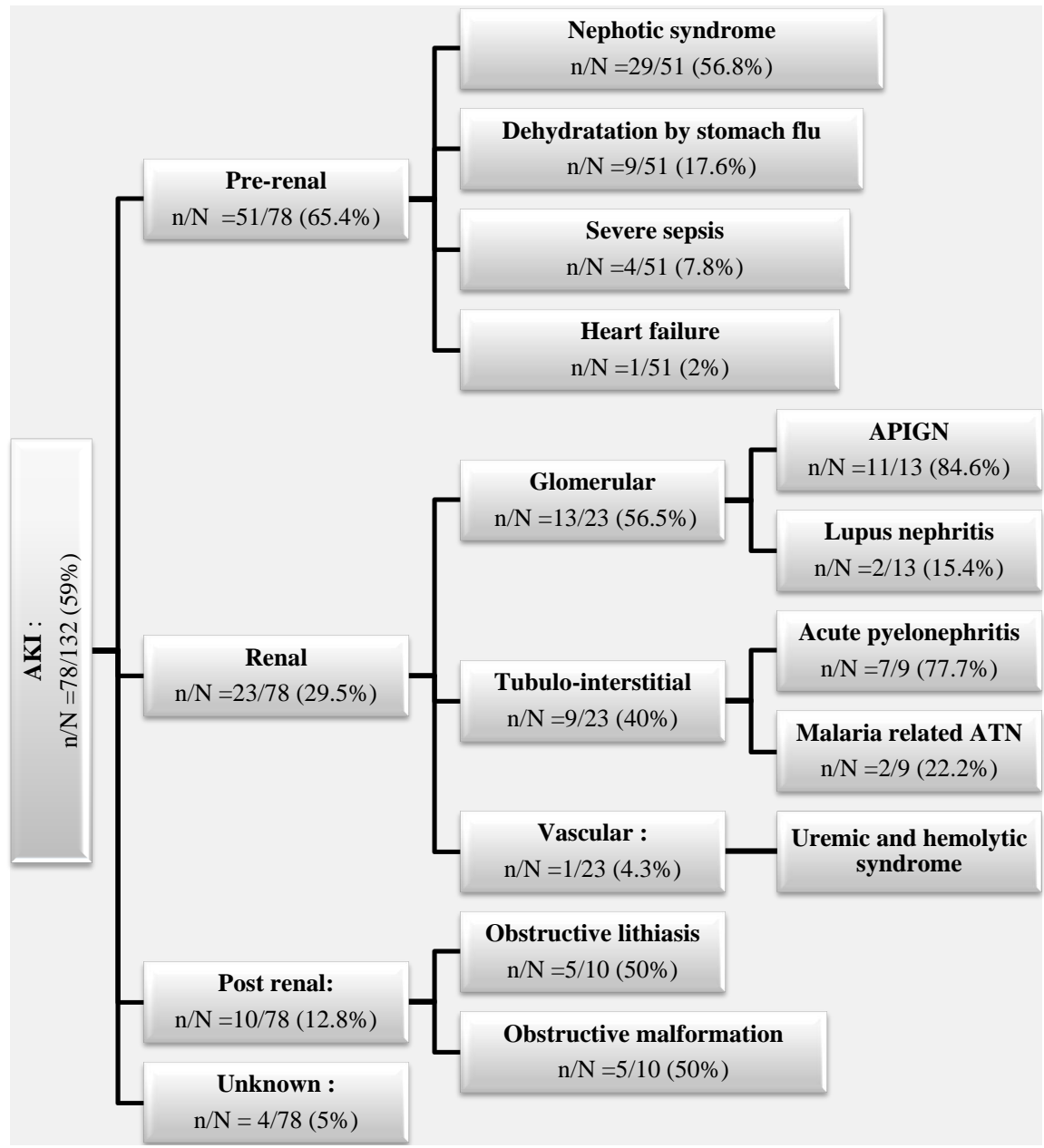

Figure 2. Frequencies and aetiologies of AKI in children according to lesion topography. AKI: acute kidney injury; APIGN: acute postinfectious glomerulonephritis; ATN: acute tubular necrosis; $\mathbf{n}=$ number of people in the variable studied; $\mathbf{N}=$ total number of people. 
stage III to $\mathrm{V}$ of which $48.1 \%(\mathrm{n} / \mathrm{N}=13 / 27)$ were from the outset admitted to dialysis (Table 2). The aetiologies were dominated by primary focal segmental glomerulosclerosis (FSGS) at 53.7\% $(\mathrm{n} / \mathrm{N}=29 / 54)$, congenital renal hypoplasia at $22.2 \%(\mathrm{n} / \mathrm{N}=12 / 54)$ and reflux nephropathy at $29.4 \%(\mathrm{n} / \mathrm{N}=5 / 17)$ (Figure 3). Late-onset access to dialysis treatment was $54 \%(\mathrm{n} / \mathrm{N}=7 / 13)$, of which $71.4 \%$ were on haemodialysis and $28.6 \%$ on continuous ambulatory peritoneal dialysis (CAPD). The need for dialysis was unmet in $46 \%(\mathrm{n} / \mathrm{N}=6 / 13)$. CKD global mortality was $29.6 \%(\mathrm{n} / \mathrm{N}=8 / 27)$ (Table 1$)$. In case of no access to dialysis treatment, mortality was $67 \%(\mathrm{n} / \mathrm{N}=4 / 6)$.

Table 2. Distribution of children with chronic kidney failure by CKD stage.

\begin{tabular}{ccc}
\hline CKD stage & n & $\%$ \\
\hline CKD Stage 2 & 27 & 50 \\
CKD Stage 3 & 9 & 16.6 \\
CKD Stage 4 & 5 & 09.2 \\
CKD Stage 5 (End of stage RF) & 13 & 24.1 \\
TOTAL & 54 & 100 \\
\hline
\end{tabular}

CKD: chronic kidney disease; RF: renal failure.

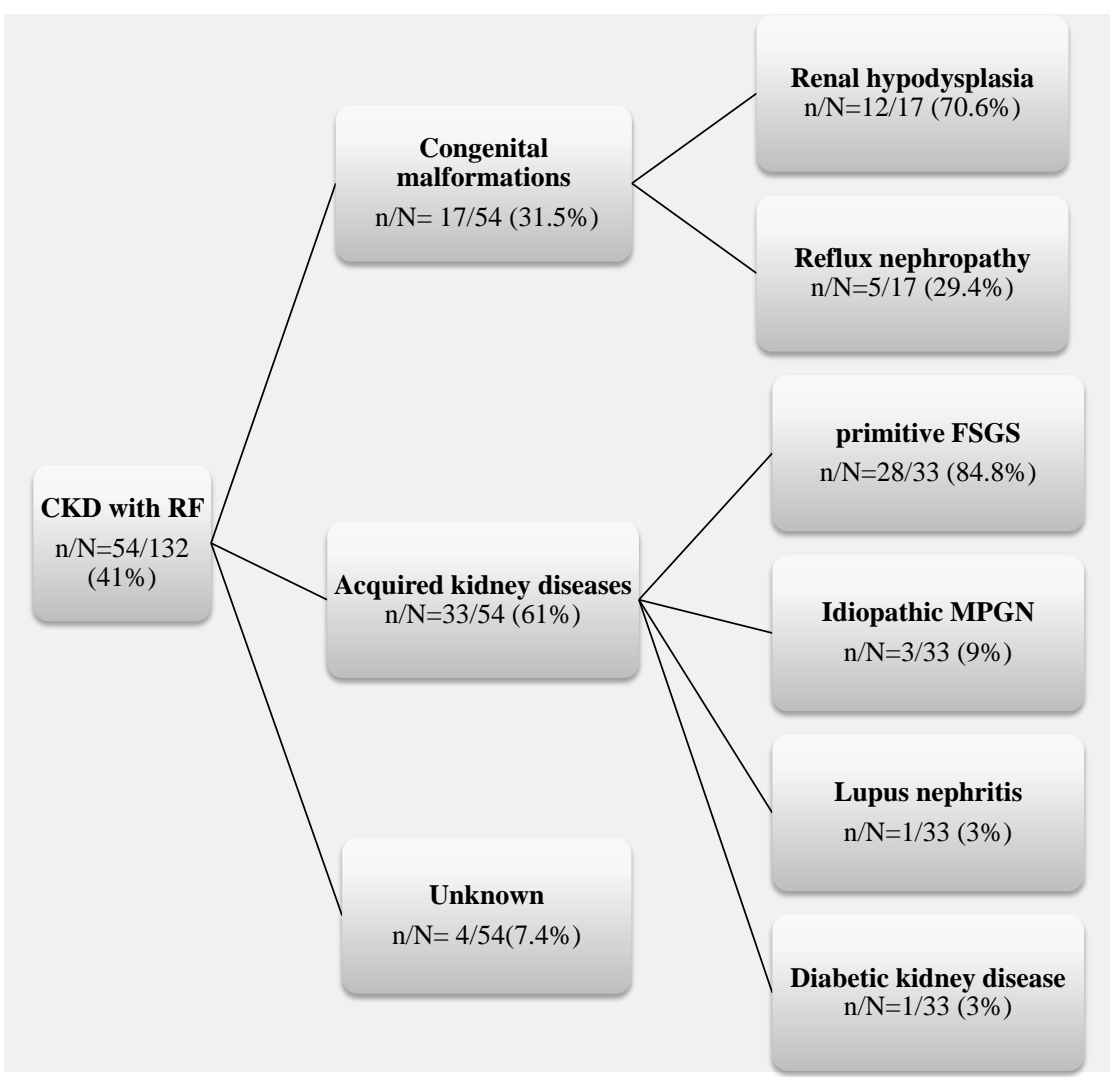

Figure 3. Frequencies and aetiologies of CKD with renal failure in children. CKD: chronic kidney disease; NS: nephrotic syndrome; FSGS: focal segmental glomerulosclerosis; MPGN: membranoproliferative glomerulonephritis; $\mathrm{n}=$ number of people in the variable studied; $\mathrm{N}=$ total number of people. 


\section{Discussion}

\subsection{Characteristics of Acute Kidney Injury}

\section{Prevalence}

GFR was impaired in $60 \%$ of the children in our study. AKI was present in slightly more than half of the cases. The prevalence of AKI is variously assessed in the literature. Indeed, most data come from intensive care units, post-surgical intensive care units, neonatology units or nephrology units. The type of children recruitment there is different from one unit to another [13]. In that respect, the prevalence of AKI in an unselected population is particularly high, around 40\%, and requires renal replacement therapy (RRT) in just under $20 \%$ of cases [12]. In a meta-analysis, the prevalence of AKI in children in sub-Saharan Africa was estimated at 33.7\% [14]. These results from literature inspire the need to carry out multicentre studies of an adequate level of evidence in the paediatric population not only at the community level, but also in reference services such as paediatric nephrology units in sub-Saharan Africa, while standardising research protocols. It will be necessary to adapt the definition of operational variables to our context, including the RIFLE criteria for AKI, the method of measuring serum creatinine level, the formulae for calculating GFR and their interpretation according to KDIGO [14] [15].

\section{Age and sex}

The mean age of children in our series was $6.5 \pm 4.77$ years. This result is similar to Bunchmann's study in Alabama, which found a mean age of 6.16 years [16]. It is therefore desirable to develop preventive and screening strategies in our context, to avoid certain forms of curable acute kidney disease that can potentially affect the child's vital prognosis or worsen the functional prognosis of the kidney with the risk of chronicity. The male predominance is respected in this study as found in most of the literature [17].

\section{Etiological aspects}

Pre-renal and renal causes were the main aetiologies of AKI in our study. This result was found in Africa and Senegal literature [15] [17]. We noted that most causes of RF such as post-infectious acute glomerulonephritis, haemolytic uraemic syndrome (HUS) and stomach flu, are accessible to prevention [18]. To this end, we need to develop simple and low-cost prevention strategies in terms of public health.

\section{Unmet need for dialysis and mortality}

AKI mortality in our study was $14.1 \%$. It was $34 \%$ in the results of Olowu et al in sub-Saharan Africa [15]. Despite its reversible nature, AKI contributes to approximately 1.7 million deaths each year worldwide. Thus, the International Society of Nephrology has made the initiative "Oby25" (zero preventable deaths from acute kidney injury by 2025), a human right and particularly a child's right [19]. The Save Young Live (SYL) programme has been launched to save children's lives by providing access to renal replacement therapy through training in peritoneal dialysis acutely and dissemination of the technique [19]. This pro- 
gramme can be implemented in targeted and trained health facilities, but especially in paediatric nephrology units where the need for dialysis is certainly increased due to the numerous referrals. In our situation, the unmet need for dialysis was $50 \%$. In case of need for dialysis, AKI mortality was $73 \%$ in Olowu's study and $78.5 \%$ in ours. When dialysis is available, most receive haemodialysis (HD). This can be explained by the absence of peritoneal dialysis in many centres [15]. It is, therefore, necessary to implement this SYL programme in Senegal, especially since consumables are free for children and families. This will require a good organisation of the activity and a multidisciplinary involvement, notably paediatrician, nephropaediatrician, paediatric surgeon, urologist, resuscitator, psychologist, paramedics, dietician...).

\subsection{Characteristics of Chronic Kidney Disease at Renal Failure Stages II (Early Stage) to V (Dialysis) \\ Prevalence}

Epidemiological data on CKD in children are limited [20] [21] [22]. Some data have been reported from Nigeria and South Africa [22] [23]. The prevalence of CKD with RF was $24.5 \%$ in our study. A better understanding of the prevalence of CKD in the paediatric population would allow the development of prevention and screening policies.

\section{Age and sex}

In our study, the mean age of children was $8.68 \pm 4.74$ years. The mean age during CKD was $10.6 \pm 3.46$ years in Senegal in 2014 [24]. After the infantile period, children more frequently develop acquired kidney disease or express a late-diagnosed congenital and/or hereditary kidney disease phenotype. It is therefore desirable to extend prevention and screening programmes to older children to avoid some forms of chronic kidney disease [24] [25].

The sex ratio in our work was 2.6. In general, there is a male predominance in childhood CKD (sex ratio $=1.5$ to 3 depending on the study) reflecting the preponderance of boys among children with CAKUT (Congenital abnormalities of the kidney and urinary tract) [26]. The male predominance is respected in this study as found in most of the literature worldwide regardless of the type of kidney disease [17].

\section{Etiological aspects}

Paediatric CKD aetiologies are different from those of adults. Congenital malformations and hereditary nephropathies were the leading causes in the United States in 2012. FSGS was the main renal lesion found in chronic glomerulopathy. The same aetiologies were found in Europe [26]. Congenital abnormalities of the kidney and urinary tract (CAKUT) account for $50 \%-60 \%$. The other major causes are glomerular kidney disease $(5 \%-15 \%)$ and hereditary kidney disease $(10 \%-$ $20 \%$ ) [26]. In Turkey, the causes were represented by malformative uropathies, renal hypoplasia and hereditary nephropathies [27]. Infectious causes have been reported in some low-income countries [28]. In our study, the main aetiologies were primary FSGS, renal hypoplasia and uropathy. 


\section{Unmet need for dialysis and mortality}

The incidence of paediatric stage 5 CKD (ESRD) requiring dialysis or renal transplantation varies widely between countries but is around 5 to 10 new cases per million children and year [26] [29]. Lately, dialysis access was 54\%, with $71.4 \%$ on haemodialysis and $28.6 \%$ on continuous ambulatory peritoneal dialysis (CAPD). The unmet need for dialysis was $46 \%$. The overall mortality of CKD was $29.6 \%$ in the hospital. The one-year survival rate in chronic haemodialysis was estimated to be low in Senegal (34.3\%) [24], due to lack of adapted equipment, low availability and high cost of erythropoiesis-stimulating agents. Also, the absence of nutritional and psycho-affective support could largely explain this low survival in pediatric chronic dialysis in Dakar [24] [30].

\subsection{Limitation of the Study}

The monocentric characteristic of the study is a limitation of the epidemiological study. The data obtained reflect hospital prevalence. Diuresis has not been taken into account as criteria for defining renal failure.

\section{Conclusion}

Screening by systematically calculating GFR showed a high prevalence of RF in children admitted to the pediatric nephrology unit in Dakar. Some aetiologies of AKI identified in our study can be prevented. Although renal replacement therapy is free of charge in Senegal and the passing law authorising renal transplantation since 2015, dialysis access is only met in half of the cases for children with renal failure. We therefore recommend: first of all, to systematically screen for $\mathrm{RF}$ and satisfy the need for dialysis in paediatrics dedicated centres, then, to fight against the avoidable causes of RF, especially those of AKI.

\section{Conflicts of Interest}

The authors declare no conflicts of interest regarding the publication of this paper.

\section{References}

[1] Crosby, L., Baker, P., Hangoma, P., Barasa, E., Hamidi, V. and Chalkidou, K. (2020) Dialysis in Africa: The Need for Evidence-Informed Decision Making. The Lancet Global Health, 8, e476-e477. https://doi.org/10.1016/S2214-109X(20)30058-9

[2] Ashuntantang, G., Osafo, C., Olowu, W.A., Arogundade, F., Niang, A., Porter, J., et al. (2017) Outcomes in Adults and Children with End-Stage Kidney Disease Requiring Dialysis in Sub-Saharan Africa: A Systematic Review. The Lancet Global Health, 5, e408-e417. https://doi.org/10.1016/S2214-109X(17)30057-8

[3] Haute Autorité de Santé(2012) Guide du parcours de soins-Maladie Rénale Chronique de l'adulte. Haute Autorité de Santé.

[4] Schwartz, G.J., Munoz, A., Schneider, M.F., Mak, R.H., Kaskel, F., Warady, B.A., et al. (2009) New Equations to Estimate GFR in Children with CKD. Journal of the American Society of Nephrology, 20, 629-637.

https://doi.org/10.1681/ASN.2008030287 
[5] Schwartz, G.J., Schneider, M.F., Maier, P.S., Moxey-Mims, M., Dharnidharka, V.R., Warady, B.A., et al. (2012) Improved Equations Estimating GFR in Children with Chronic Kidney Disease Using an Immunonephelometric Determination of Cystatin C. Kidney International, 82, 445-453. https://doi.org/10.1038/ki.2012.169

[6] Bargnoux, A.S., Boutten, A., Cambillau, M., Carlier, M.C., Cavalier, E., Cristol, J.P., et al. (2011) Recommendations for the Selection and Alignment Techniques for the Determination of Creatinine. Annales de Biologie Clinique, 69, 9-16.

https://doi.org/10.1684/abc.2010.0510

[7] Bacchetta, J., Cochat, P., Rognant, N., Ranchin, B., Hadj-Aissa, A. and Dubourg, L. (2011) Which Creatinine and Cystatin C Equations Can Be Reliably Used in Children? Clinical Journal of the American Society of Nephrology, 6, 552-560. https://doi.org/10.2215/CJN.04180510

[8] Mazzachi, B.C., Peake, M.J. and Ehrhardt, V. (2000) Reference Range and Method Comparison Studies for Enzymatic and Jaffe Creatinine Assays in Plasma and Serum and Early Morning Urine. Clinical Laboratory, 46, 53-55.

[9] Schwartz, G.J., Brion, L.P. and Spitzer, A. (1987) The Use of Plasma Creatinine Concentration for Estimating Glomerular Filtration Rate in Infants, Children, and Adolescents. Pediatric Clinics of North America, 34, 571-590. https://doi.org/10.1016/S0031-3955(16)36251-4

[10] Langlois, V. (2008) Laboratory Evaluation at Different Ages. In: Geary, D.F. and Schaefer, F., Eds., Comprehensive Pediatric Nephrology, Elsevier, Mosby, 39-54. https://doi.org/10.1016/B978-0-323-04883-5.50008-8

[11] Hogg, R.J., Furth, S., Lemley, K.V., Portman, R., Schwartz, G.J., Coresh, J., et al. (2003) National Kidney Foundation's Kidney Disease Outcomes Quality Initiative Clinical Practice Guidelines for Chronic Kidney Disease in Children and Adolescents: Evaluation, Classification, and Stratification. Pediatrics, 111, 1416-1421. https://doi.org/10.1542/peds.111.6.1416

[12] Van Vong, L., Osman, D., Vinsonneau, C. and Groupe d'experts (2014) Épuration extrarénale en réanimation adulte et pédiatrique. Recommandations formalisées d'experts sous l'égide de la Société de réanimation de langue française (SRLF), avec la participation de la Société française d'anesthésie-réanimation (Sfar), du Groupe francophone de réanimation et urgences pédiatriques (GFRUP) et de la Société francophone de dialyse (SFD). Réanimation, 23, 714-737. https://doi.org/10.1007/s13546-014-0917-6

[13] Chertow, G.M., Soroko, S. and Paganini, E.P. (2006) Mortality after Acute Renal Failure: Models for Prognostic Stratification and Risk Adjustment. Kidney International, 70, 1120-1126. https://doi.org/10.1038/sj.ki.5001579

[14] Eknoyan, G., Lameire, N., et al. (2013) KDIGO 2012 Clinical Practice Guideline for the Evaluation and Management of Chronic Kidney Disease. Kidney International, 3, 1-150.

[15] Olowu, W.A., Niang, A., Osafo, C., Ashuntantang, G., Arogundade, F.A., Porter, J., et al. (2016) Outcomes of Acute Kidney Injury in Children and Adults in SubSaharan Africa: A Systematic Review. The Lancet Global Health, 4, e242-e250. https://doi.org/10.1016/S2214-109X(15)00322-8

[16] Bunchmann, T., Mcbryde, K.D., Mottes, T.E., Gardner, J.J., Maxvold, N.J. and Brophy, P.D. (2001) Pediatric Acute Renal Failure: Outcome by Modality and Disease. Pediatric Nephrology, 16, 1067-1061. https://doi.org/10.1007/s004670100029

[17] Coulibaly, P.N.A., Cisse, L., Diarassouba, G., Egesi, M., Tia, W.M., Ouattara, G.J., et al. (2015) Maladies rénales et urinaires des enfants hospitalisés au service de pédiatrie du CHU de Treichville (Abidjan). Médecine d Afrique Noire, 6, 321-326. 
[18] Chan, J.C.M., Williams, D.M. and Roth, K.S. (2002) Kidney Failure in Infants and Children. Pediatrics in Review, 23, 47-60.

[19] Mehta, R.L., Cerda, J., Burdmann, E.A., Tonelli, M., García-García, G., Jha, V., et al. (2015) International Society of Nephrology's 0by25 Initiative for Acute Kidney Injury (Zero Preventable Deaths by 2025): A Human Rights Case for Nephrology. Lancet, 385, 2616-2643.

[20] Frimat, L., Loos-Ayav, C., Briançon, S. and Kessler, M. (2005) Épidémiologie des maladies rénales chroniques. EMC-Néphrologie, 2, 139-157. https://doi.org/10.1016/j.emcnep.2005.09.003

[21] Cochat, P., Cazet, F. and Liutkus, A. (2005) Néphrologie pédiatrique dans les pays en développement. Archives de Pédiatrie, 12, 723-725. https://doi.org/10.1016/j.arcped.2005.04.061

[22] Anochie, I. and Eke, F. (2003) Chronic Renal Failure in Children: A Report from Port Harcourt, Nigeria (1985-2000). Pediatric Nephrology, 18, 692-695. https://doi.org/10.1007/s00467-003-1150-0

[23] Bhimma, R., Adhikari, M., Asharam, K. and Connolly, C. (2000) The Spectrum of Chronic Kidney Disease (Stages 2-5) in KwaZulu-Natal, South Africa. Pediatric Nephrology, 23, 1841-1846. https://doi.org/10.1007/s00467-008-0871-5

[24] Keita, Y., Sylla, A., Seck, A., Cissé, M.M., Lemrabott, A.T., Ndongo, A.A., et al. (2014) Aspects épidémiologiques, cliniques et évolutifs de l'insuffisance rénale chronique (IRC) chez l'enfant dans un hôpital pédiatrique sénégalais. African Journal of Paediatric Nephrology, 1, 83-89.

[25] Keijzer-Veen, M.G., Schrevel, M., Finken, M.J., Dekker, F.W., Nauta, J., Hille, E.T., et al. (2005) Collaborative Study Group (2005) Microalbuminuria and Lower Glomerular Filtration Rate at Young Adult Age in Subjects Born Very Premature and after Intrauterine Growth Retardation. Journal of the American Society of Nephrology, 16, 2762-2768. https://doi.org/10.1681/ASN.2004090783

[26] Harambat, J., van Stralen, K.J., Kim, J.J. and Jane Tizard, E. (2012) Epidemiology of Chronic Kidney Disease in Children. Pediatric Nephrology, 27, 363-373.

https://doi.org/10.1007/s00467-011-1939-1

[27] Bek, K., Akman, S., Bilge, I., Topaloğlu, R., Calişkan, S., Peru, H., et al. (2009) Chronic Kidney Disease in Children in Turkey. Pediatric Nephrology, 24, 797-806. https://doi.org/10.1007/s00467-008-0998-4

[28] Ali, El-T.M.A., Abdelraheem, M.B., Mohamed, R.M., Hassan, E.G. and Watson, A.R. (2009) Chronic Renal Failure in Sudanese Children: Aetiology and Outcomes. Pediatric Nephrology, 24, 349-353. https://doi.org/10.1007/s00467-008-1022-8

[29] Dussol, B. (2011) Différents stades de l'insuffisance rénale chronique: Recommandations. Immuno-analyse \& Biologie Spécialisée, 26, 55-59.

https://doi.org/10.1016/j.immbio.2010.12.003

[30] Keita, Y., Ka, E.F., Ly, F., Kane, Y., Ndongo, A.A., Lemrabott, A.T., et al. (2020) Etat des lieux de l'hémodialyse chronique pédiatrique au Sénégal: Enquête rétrospective. Pan African Medical Journal, 2, Article No. 72.

https://doi.org/10.11604/pamj-cm.2020.2.72.20948 